\title{
How Does Global Disinflation Drag Inflation in Small Open Economies?*
}

\author{
Marco Vega \\ LSE and Central Bank of Peru \\ and \\ Diego Winkelried \\ Central Bank of Peru
}

This version, March 2004

\begin{abstract}
This paper shows the way how persistent world inflation shocks hitting a small open economy can re-weight the importance of domestic and foreign factors in the determination of prices. In this sense, we study why the recently observed global disinflation environment may imply a weakening of the standard interest rate channel of monetary policy to affect inflation.

We derive a state-dependent Phillips curve based on translog preferences that make the elasticity of substitution of domestic goods sensitive to foreign prices. With this approach we are able to replicate the dragging effect of global disinflation on domestic inflation, as experienced in small open economies such as New Zealand, Chile and Peru.
\end{abstract}

JEL Classification: E31, E52.

Keywords: Monetary Policy, Phillips Curve, Translog Preferences.

\footnotetext{
${ }^{*}$ We are indebted to Piti Disyatat, Charles Goodhart, Paul Castillo, Vicente Tuesta, Hugo Perea, Javier Luque and Daniel Barco for their valuable comments and suggestions. The opinions expressed herein are those of the authors and not necessarily represent those of the Central Bank of Peru.
} 


\section{Introduction}

As compared to decades gone, many economies are nowadays characterised by low inflation environments. The reasons for this global disinflation phenomenon have been pointed out by, among others, Andersen and Wascher (2001), Bowman (2003) and Rogoff (2003). There are several factors laying behind this scenario, such as structural changes in the inflation processes, institutional factors (increasing central bank independence and strong commitment to anti-inflationary strategies) and the increased competitiveness or market power hypothesis in price setting behaviour. According to this hypothesis, both the rising globalisation and deregulation witnessed worldwide in the 90's have contributed to the fall in the market power of price setting firms. As a result, inflation rates have been unusually persistent at very low levels (below targets), barely reacting to expansionary monetary policies. This fact has been particularly peculiar in small open economies such as New Zealand and Australia from 1997 to 1999 as well as Chile and Peru during the first years of the 2000's ${ }^{1}$.

There are at least two ways to tackle the increased competitiveness hypothesis. The first one is related to the behavior of markups vis-a-vis inflation. A pioneering result offered in Rotemberg and Woodford (1991) for a closed economy is that aggregate markups are countercyclical $^{2}$. This contrasts the views in Taylor (2000) and Jonsson and Palmqvist (2003) for open economies, where lower inflation rates imply lower market power. In general, the markup debate is not conclusive.

A convenient alternative route of analysis adopted in our paper is to leave aside the behaviour of markups and note that the increased competitiveness hypothesis also relies on the rising number of good varieties faced by consumers due to globalisation. The implication of this casual observation is that consumers are more prone to substitute away their consumption towards newer and cheaper goods ${ }^{3}$. The contribution of our paper hinges precisely on modelling a simple mechanism explaining the change in the substitutability among imported and home goods and their implications for aggregate inflation and monetary policy.

The usual device for modelling inflation dynamics is the well-known New Keynesian Phillips Curve. Although its standard version has many advantages such as mathematical tractability, it usually fails in replicating inflation persistence ${ }^{4}$. Besides, it is common even in the newest approaches, to assume that the demands for goods produced by monopolistic firms arise from Constant Elasticity of Substitution (CES) preferences, which seems to be an inappropriate assumption within the increased competitiveness context.

\footnotetext{
${ }^{1}$ More examples can be found in Rogoff (2003).

${ }^{2}$ This means that booms represent periods of falling market power whereas recessions picture episodes of rising market power. Bénabeau (1992) and Banerjee and Russell (2003) also find the negative relationship.

${ }^{3}$ See Kamada and Hirakata (2002) for an empirical overview of the increased competitiveness phenomenon for the Japanese economy. For the USA, Broda and Weinstein (2004) find that import prices have fallen faster than what official statistics suggest due to the increase in the imported goods varieties.

${ }^{4}$ Though, some proposals have arisen to overcome this limitation such as Mankiw and Reis (2001) sticky information approach or Calvo et. al. (2003) rational inertia theory.
} 
We instead study inflation dynamics by means of a modelling tool that relies on translog preferences leading to a state-dependent Phillips curve for a small open economy. The advantage of the translog specification over the widely used CES counterpart is that it allows the demands for goods to depend on the prices of other goods and thereby making the price elasticity of domestically produced goods dependent on price movements elsewhere. As pointed out by Bergin and Feenstra $(2000,2001)$, the use of such an aggregator is useful to generate endogenous persistence.

In the light of this type of preferences, a world disinflation environment characterised by frequent disinflation shocks ${ }^{5}$, induces a strong strategic complementarity, namely, home producers having to optimally follow up the world price trend ${ }^{6}$. The identification of this dragging effect of world inflation results crucial for the understanding of monetary policy in sufficiently small open economies. Once home inflation has been pushed down severely, monetary policy has a mixed blessing: in one hand, it can enjoy the benefit of low world inflation and in the other hand, it will soon learn that pushing up inflation with its standard domestic interest rate instrument gets harder and harder. One obvious way to push up inflation in such circumstances is to use the one channel that gets stronger: the pass-through from the exchange rate to inflation, precisely the way they might less be willing to be heading for.

Before proceeding, it is important to have a better grasp of the differences between the dragging and the pass-through effects. For a small open economy, world inflation fluctuations quickly hit tradable goods prices which are then - albeit with lags - aggregated out to affect overall inflation. This is the well-known pass-through effect ${ }^{7}$ which does not directly impact on nontradable goods pricing. In contrast, if world inflation also affects non-tradable goods prices, the consequences for overall inflation are stronger. We dub this impact as the dragging effect.

The rest of the paper is organised as follows. Section 2 provides some empirical evidence to support the increased competitiveness hypothesis in three small open economies. Section 3 develops partial-equilibrium Phillips curve derivations based on both the CES and the translog aggregator. In section 4 we perform world disinflation experiments to study the effects upon the variables of interest and in particular the power of monetary policy to affect inflation ${ }^{8}$. Section 5 contains our final remarks and suggests some lines of further research.

\section{Empirical motivation}

The above discussion recalls the recurrent debate about the non-linearity of the Phillips curve. As pointed out by Dupasquier and Ricketts (1998), several models of price-setting behaviour

\footnotetext{
${ }^{5}$ For example, the constant appearance of cheap foreign products competing with local ones or the constant innovation in information-based products.

${ }^{6}$ See Bakhshi et. al. (2003) for a discussion on strategic complementarities in the presence of trend inflation.

${ }^{7}$ See Goldfjan and Ribeiro (2000) for a review of the pass-through literature.

${ }^{8}$ Throughout the paper, the term monetary policy power does not refer to the power to affect aggregate demand but the power to affect inflation.
} 
suggest that the parameters of the Phillips curve are functions of macroeconomic conditions ${ }^{9}$ such as the level of inflation and, in an open economy, the real exchange rate ${ }^{10}$. These nonlinearities may lessen the accuracy of the traditional CES-based New Keynesian Phillips curve as a sensible modelling and forecasting tool, particularly in small economies with significant disinflation episodes ${ }^{11}$.

To provide some empirical basis for this point, we perform a time-varying-parameter inflation equation estimation for three small open economies with inflation-targeting regimes: New Zealand, Chile and Peru. The empirical specification is the following linear-homogenous Phillips curve ${ }^{12}$

$$
\pi_{t}=a_{t} \pi_{t+1}+\left(1-a_{t}\right) \pi_{t-1}+b_{0, t} \Delta \varpi_{t}+b_{1, t} \Delta \varpi_{t-1}+c_{0, t} \pi_{w, t}+c_{1, t} \pi_{w, t-1}+i i d
$$

with random-walk coefficients ${ }^{13}$

$$
\begin{array}{ll}
a_{t}=a_{t-1}+i i d & \\
b_{j, t}=b_{j, t-1}+i i d & \text { for } j=0,1 \\
c_{j, t}=c_{j, t-1}+i i d & \text { for } j=0,1
\end{array}
$$

Quarterly data were obtained from the International Financial Statistics database and the estimation sample includes the low inflation or disinflation years of the 90's. In all cases, we used the headline CPI inflation as the dependent variable $\pi_{t}$ and estimated the moving parameters via Kalman filtering ${ }^{14}$.

Two comments are worth-mentioning. First, the marginal cost indicator in [1] is the growth rate of real wages $\Delta \varpi_{t}$, so the parameter $\left(b_{0, t}+b_{1, t}\right)$ is the slope of the Phillips curve. For a robustness check, we tried alternative measures such as real output, unemployment or real wage gaps and growth rates, with no qualitative differences in the results. Second, $\pi_{w, t}$ is the foreign inflation expressed in local currency (i.e. plus nominal depreciation), so the sum of the last two coefficients in [1] $\left(c_{0, t}+c_{1, t}\right)$ captures the pass-through effect of foreign price shocks.

Figure [1] presents the estimated paths for the Phillips curve slopes together with the behaviour of relative prices, measured as the effective real exchange rate (in logs) ${ }^{15}$. The most

\footnotetext{
${ }^{9}$ Amongst the most popular explanations of such asymmetries are signal extraction or misperceptions, adjustment costs, downward nominal wage rigidities and the presence of monopolistically competitive markets. More details can be found in King and Watson (1994) and Clark and Laxton (1997).

${ }^{10}$ Another important condition for an open economy is studied in Razin and Yuen (2001). They analyse why countries with greater restrictions on capital mobility tend to have steeper Phillips curves.

${ }^{11}$ See Ascari (2000) for further discussion.

${ }^{12}$ Equation [1] is similar to the equations derived in the theoretical model outlined in Section 3.

${ }^{13}$ The iid symbol must be understood henceforth as a zero-mean perturbation with constant variance and independent on its own lags and leads as well as with any other variable.

${ }^{14}$ As they are treated as states variables in state-space framework. See Harvey (1989).

${ }^{15}$ We measure the real effective exchange rate as the ratio of the domestic currency price index of foreign goods to the domestic price index (so an increase in the ratio implies a real depreciation). The price index of foreign goods is calculated using a weighted average of the price indices of main trade partners. We have re-scaled the real exchange rate so it equals 100 (in levels) in the first quarter of 1994.
} 
remarkable feature is the high correlation between these two indicators, which suggests that the state-dependency of the Phillips curve slope is related to factors affecting the real exchange rate. The reason behind this finding is that in an open economy Phillips curve such as [1], the slope parameter could be interpreted as a measure of the importance of domestic factors in the formation of prices. A fall in the price of tradables or a rise in the price of non-tradables leads to demand substitution, implying a higher share of tradable goods in domestic expenditure. Therefore, foreign shocks disturbing tradable prices would become more important in equilibrium determination. As a result, the Phillips curve becomes more elastic (its slope falls). In addition, Figure [2] depicts the time paths of the pass-through from foreign inflation to headline inflation. As expected, the alluded path is negatively correlated with the real exchange rate ${ }^{16}$.

In a nutshell, we can see that movements in the real exchange rate are related to both the passtrough and the slope of the Phillips curve in opposite ways, and in so doing, they continuously re-weight the contribution of external and domestic factors in the determination of prices and inflation.

Given that the fall in the slope of the Phillips curve originated from relative price fluctuations ends up weakening a channel whereby domestic shocks affect headline inflation, monetary policy may lose effectiveness. Regardless of the expectation or exchange rate transmission mechanisms implied in the Phillips curve, monetary policy also affects inflation through the demand channel, so the lower the slope is, the weaker the standard interest rate instrument is. In other words, the power of the interest rate instrument is inversely related to the dragging effect of world inflation ${ }^{17}$. We shall study this fact formally in the subsequent sections.

\section{Theoretical derivation of inflation processes}

In this section we analyse the relationship between the relative price of tradables to nontradables $^{18}$ and the power of domestic factors (including monetary policy) to explain inflation. The goal is to provide a theoretical framework consistent with the empirical findings provided in section 2 .

The framework set up here tries to be as simple as possible. The aim is to build a partial equilibrium model to derive microfounded inflation equations to be used in the next section where a stylised general equilibrium model is set up. The emphasis is on aggregation features generated from two tentative assumptions for consumer preferences. Each one has different implications concerning the substitutability among goods and in turn, different effects on the Phillips curve parameters. We work with two types of goods - a home, non-tradable good and a world, tradable good - which enter into the consumption basket according to either a CES

\footnotetext{
${ }^{16}$ This result is in line with empirical findings in Goldfjan and Ribeiro (2000).

${ }^{17}$ In an open economy, it is known that the degree of price stickiness is lower due to the presence of imported goods and nominal exchange rate fluctuations. Since real effects of monetary policy shocks occur mainly because of nominal rigidities, the decline of monetary policy effectiveness may be reflecting the decrease of overall price stickiness implied by the dragging effect.

${ }^{18}$ This ratio is the theoretical counterpart of the effective real exchange rate used in the empirical section.
} 
(which will be treated as a benchmark) or translog aggregator. As mentioned, a key feature of the translog specification is that the implied price elasticities are state-dependent as opposed to the CES case.

The price of the world good obeys the law of one price. That is, if $P_{t}^{*}$ denotes the international price of the world good and $S_{t}$ is the nominal exchange rate, then the price in pesos ${ }^{19}$ of the world good is $P_{w, t}=S_{t} P_{t}^{*}$. On the other side, to model stickiness in home prices, we adopt the cost-of-changing-prices setup of Rotemberg (1982). This approach consists first in finding desired prices, as if having firms operating in a flexible price environment, and then introducing costs of adjustment to move observed prices towards the optimal ones.

Two further simplifying assumptions are made to derive analytically tractable inflation equations. The first one is the linearity of the home good production function. This assumption shuts off the direct demand effect on marginal costs and hence on prices ${ }^{20}$. Since the effect is virtually the same under both aggregators, the gains from working with the standard concave production function are negligible to our purpose. Moreover, provided that both preference assumptions do not qualitatively make difference in the sensitive parts of marginal costs, we assume a given labour demand. The second assumption is that we define real domestic wages in terms of the home price rather than the consumption price. This assumption allows us to derive inflation equations that are easy to handle and interpret.

Throughout the document, lower cases of both real quantities and prices refer to the natural logarithms of the respective upper cases. Also, the $h$ and $w$ subscripts refer to home and world variables respectively. The details of the analytical derivations are outlined in the Appendix.

\subsection{Inflation dynamics with a CES aggregator}

\section{Preferences and aggregation}

Under the CES consumption aggregator, the consumption of the home good $C_{h, t}$ depends negatively on its own price $P_{h, t}$ and positively on the aggregate consumption $C_{t}$. Specifically,

$$
c_{h, t}=\ln (1-\alpha)-\eta\left(p_{h, t}-p_{t}\right)+c_{t}
$$

where $p_{t}$ is the log aggregate CPI. In this equation $\eta>1$ measures the degree of substitutability between the two goods and $\alpha \in\langle 0,1\rangle$ is usually interpreted as the degree of openness ${ }^{21}$.

It is easy to show that if the steady-state relative price level $P_{h, t} / P_{w, t}$ is constant and uniquely equal to one, the consumer-based price inflation can be approximated by

$$
\pi_{t}=(1-\alpha) \pi_{h, t}+\alpha \pi_{w, t}
$$

\footnotetext{
${ }^{19}$ We will refer to the local currency of our small open economy simply as the "peso".

${ }^{20}$ In the standard New-Keynesian Phillips curve, price dynamics is affected by real marginal cost movements, which in turn, is affected by aggregate demand.

${ }^{21}$ See, for instance, Romer (1993).
} 
The overall inflation dynamics does depend on $\alpha$ but not on $\eta$. Thus, under CES preferences, the degree of goods substitutability plays no fundamental role in aggregate dynamics.

\section{World inflation}

World inflation follows a simple AR(1) process,

$$
\pi_{t}^{*}=(1-\rho) \bar{\pi}+\rho \pi_{t-1}^{*}+\epsilon_{t} \text { with } \epsilon_{t} \sim i i d
$$

where $|\rho|<1$ and $\bar{\pi}$ is the steady-state world inflation rate.

It is important to recall that the world inflation expressed in pesos $\pi_{w, t}$ appearing in [4] is given by $\Delta s_{t}+\pi_{t}^{*}$.

\section{Home firms and flexible price setting}

The domestic good producer is endowed with monopolistic power and sets its price accordingly. Production $Y_{h, t}$ is made with a technology that exhibits constant returns on labour. So, for given nominal wages $W_{t}$, the total nominal cost is

$$
\operatorname{Cost}_{h}\left(Y_{h, t}\right)=W_{t} Y_{h, t}
$$

Every period, the domestic producer chooses its price to maximise profits,

$$
\max _{P_{h, t}}\left[B\left(P_{h, t}\right)=P_{h, t} Y_{h, t}\left(P_{h, t}\right)-\operatorname{Cost}_{h}\left(Y_{h, t}\left(P_{h, t}\right)\right)\right]
$$

Given that in equilibrium $Y_{h, t}=C_{h, t}$, the optimal price decision reduces to the standard markup pricing over marginal cost. If we take logs to the markup pricing equation we obtain the working expression

$$
p_{h, t}^{c e s}=\ln \mu+w_{t}
$$

where $\mu$ is the flexible-price markup $\mu=\frac{\eta}{\eta-1}$.

As we may note later, the differentiated expression for $p_{h, t}^{\text {ces }}$ is a key variable that feeds into the inflation processes and is simply defined as

$$
\Delta p_{h, t}^{c e s}=\Delta w_{t}
$$

\section{Introducing price rigidity}

Now we suppose that firms cannot set their desired optimal price due to the existence of adjustment costs. As Rotemberg (1982), we assume that the monopolistic firm maximises profits net of the loss it incurs by inducing variability in its price path.

We perform a quadratic approximation of the monetary benefit of the firm (equation [7]) around the flexible price equilibrium (the price level that maximizes benefits in the absence 
of adjustment costs, $p_{h, t}^{\text {ces }}$. After introducing adjustment costs, the firm's problem can be reformulated into the following cost minimization program

$$
\min _{\left\{p_{h, s}\right\}_{s=t \ldots \infty}} E_{t}\left[\sum_{s=t}^{\infty} \beta^{s-t}\left\{\left(p_{h, s}-p_{h, s}^{c e s}\right)^{2}+\frac{1}{2 c}\left(p_{h, s}-p_{h, s-1}\right)^{2}\right\}\right]
$$

where $\beta \in\langle 0,1\rangle$ is the firm's discount factor and $E_{t}$ is the expectation operator.

The positive constant $c$ as well as the log of the previous period price $p_{h, t-1}$ are known at time $t$. This type of dynamic problem and its solution has been neatly outlined in Sargent (1979) and applied to inflation dynamics by Batini et. al. (2002). However, our set up is different as we do not model a continuum of homogeneous agents but just one domestic firm endowed with market power. Thus, the price aggregation we perform is different.

The optimal price plan obtained by solving problem [10] implies the following inflation process

$$
\pi_{h, t}=\left(\frac{\beta}{1+\beta}\right) E_{t}\left[\pi_{h, t+1}\right]+\left(\frac{1}{1+\beta}\right) \pi_{h, t-1}+\left(\frac{2 c}{1+\beta}\right) \Delta \varpi_{t}+\xi_{t}
$$

where $\Delta \varpi_{t}$ is the growth of real wages defined as $\varpi_{t}=w_{t}-p_{h, t}$. The term $\xi_{t}$ is a combination of iid forecast errors and is treated as a shock.

\section{The aggregate inflation process}

It is straightforward to plug [11] into the aggregator [4] to obtain

$$
\begin{aligned}
\pi_{t}= & a_{0} E_{t}\left[\pi_{t+1}\right]+\left(1-a_{0}\right) \pi_{t-1}+a_{\text {slope }} \Delta \varpi_{t} \\
& +\alpha\left[\pi_{w, t}-a_{0} E_{t}\left[\pi_{w, t+1}\right]-\left(1-a_{0}\right) \pi_{w, t-1}\right]+a_{2} \xi_{t}
\end{aligned}
$$

where:

$$
\begin{array}{ll}
a_{0} & =\beta\left[\frac{1}{1+\beta}\right] \\
a_{\text {slope }} & =(1-\alpha)(2 c)\left[\frac{1}{1+\beta}\right] \\
a_{2} & =(1-\alpha)
\end{array}
$$

Under suitable values for the structural parameters $\alpha, \beta, c, \rho$, the Phillips curve coefficients are all positive and less than unity.

The result is a standard hybrid Phillips curve with the following features: (i) it has a dynamic linear homogeneity property implying nominal neutrality in the long run; (ii) it depends on the real marginal cost defined by $\Delta \varpi_{t}$ and on the expectation shock $\xi_{t}$; and (iii) it depends on the world price inflation.

Consider now a world inflation shock $\left(\epsilon_{0}=1\right)$. According to [12] and [5], if we abstract from nominal exchange rate or other endogenous movements, the response on impact ${ }^{22}$ of aggregate

\footnotetext{
${ }^{22}$ In the pre-shock period, $\pi_{-1}=\Delta \varpi_{-1}=\pi_{w,-1}=0$. The shock implies that $\pi_{w, 0}=1+\Delta s_{0}$. Then, the response on impact over inflation is $\pi_{0}=a_{0}\left((1-\alpha) E_{t}\left[\pi_{h, 1}\right]+\alpha E_{t}\left[\pi_{w, 1}\right]\right)+\alpha\left[1+\Delta s_{0}-a_{0} E_{t}\left[\pi_{w, 1}\right]\right]=$ $a_{0}(1-\alpha) E_{t}\left[\pi_{h, 1}\right]+\alpha\left(1+\Delta s_{0}\right)$.
} 
inflation is $\alpha$. In the absence of other perturbations the shock will be partially corrected in the subsequent periods as $\pi_{w, t}$ reverts to its long-run value, due to the presence of the term $-\alpha\left(1-a_{0}\right) \pi_{w, t-1}$. Further, it is useful to recall equation [11] and note that the shock per se does not affect home prices $^{23}$. The world inflation affects the aggregate inflation by a direct pass-through effect.

\subsection{Inflation dynamics with a translog aggregator}

\section{Preferences and inflation aggregation}

With two consumption goods, the aggregate log price $p_{t}$ is defined as

$$
p_{t}=(1-\alpha) p_{h, t}+\alpha p_{w, t}-\frac{\gamma}{2}\left(p_{w, t}-p_{h, t}\right)^{2}
$$

In this aggregator, the parameters $\alpha \in\langle 0,1\rangle$ and $\gamma>0$ are such that both goods enter symmetrically in consumption preferences. Also, homogeneity in the demand functions is imposed. Since the translog can be understood as an augmented CES aggregator ${ }^{24}$, the parameter $\alpha$ is the same as in [3].

The log of the compensated demand for the domestic good is

$$
c_{h, t}=\ln \left(1-\alpha+\gamma q_{t}\right)-\left(p_{h, t}-p_{t}\right)+c_{t}
$$

This demand function differs from that under the CES specification in an important way: it depends on the relative price of the world good to the home good $q_{t}$, defined as $q_{t}=p_{w, t}-p_{h, t}$. In the long-run $q_{t}$ is constant and, for convenience, we set its steady-state value to zero. This measure proves essential in the derivation of the time-varying coefficients of the Phillips curve and hence on the power of monetary policy to affect inflation via changes in marginal costs.

The aggregation of inflation is achieved by differencing equation [13], which leads to

$$
\pi_{t}=\left(1-\alpha_{t}\right) \pi_{h, t}+\alpha_{t} \pi_{w, t}
$$

This expression resembles equation [4] for the CES case. However, the weights are timevarying now. In this case $\alpha_{t}=\alpha-\frac{1}{2} \gamma\left(q_{t}+q_{t-1}\right)$, so the inflation process is a changing weighted average of domestic and foreign inflation ${ }^{25}$. As the relative price of the world good falls, $q_{t}$ turns negative and therefore, world inflation gradually becomes more important to the determination of overall inflation.

\footnotetext{
${ }^{23}$ In a general equilibrium setting, domestic inflation would respond to changes in $\Delta \varpi_{t}$ generated, for instance, by a policy reaction to the external shock.

${ }^{24}$ See Deaton and Muellbauer (1980).

${ }^{25}$ A note of caution: For the shares of either home or world good expenditure to be bounded between zero and one, we require both $\gamma$ and $q_{t}$ not to be too large. Empirically and for practical purposes, these conditions always hold.
} 


\section{Home firms and flexible price setting}

Under translog aggregation, the non-tradable firm takes into account the fact that the demand for its good depends on the world good price. Then, the expression for the optimal change in prices under a desired flexible-price scenario is

$$
\Delta p_{h, t}^{\text {trans }}=\frac{1}{2} \pi_{w, t}+\frac{1}{2} \Delta w_{t}
$$

Namely, the optimal price change $\Delta p_{h, t}^{\text {trans }}$ is a simple average of world inflation and marginal costs growth.

\section{Introducing price rigidity}

The domestic inflation process is

$$
\begin{aligned}
\pi_{h, t}= & \left(\frac{\beta}{1+\beta+c}\right) E_{t}\left[\pi_{h, t+1}\right]+\left(\frac{1}{1+\beta+c}\right) \pi_{h, t-1}+\left(\frac{c}{1+\beta+c}\right) \pi_{w, t} \\
& +\left(\frac{c}{1+\beta+c}\right) \Delta \varpi_{t}+\zeta_{t}
\end{aligned}
$$

where $\zeta_{t}$ is an iid shock.

This equation is quite different from that in the CES case in [11]. In particular, home inflation depends positively on world inflation ${ }^{26}$. To prevent consumers from substituting away the consumption of home goods, the home producer will find optimal to follow up the world trend, so the falling world inflation drags home inflation ${ }^{27}$.

\section{The aggregate inflation process}

It is now straightforward to aggregate the inflation dynamics plugging [17] into [15] to get

$$
\begin{aligned}
\pi_{t}= & a_{0} E\left[\pi_{t+1}\right]+a_{1} \pi_{t-1}+\left(1-a_{0}-a_{1}\right) \pi_{w, t}+a_{\text {slope }, t} \Delta \varpi_{t} \\
& +\alpha_{t}\left[\pi_{w, t}-a_{0} E_{t}\left[\pi_{w, t+1}\right]-\left(1-a_{0}\right) \pi_{w, t-1}\right]+a_{2, t} \zeta_{t}
\end{aligned}
$$

where

$$
\begin{array}{ll}
a_{0} & =\beta\left[\frac{1}{1+\beta+c}\right] \\
a_{1} & =\left[\frac{1}{1+\beta+c}\right] \\
a_{\text {slope }, t} & =\left(1-\alpha_{t}\right) c\left[\frac{1}{1+\beta+c}\right] \\
a_{2, t} & =1-\alpha_{t}
\end{array}
$$

\footnotetext{
${ }^{26}$ The degree of dependence is captured by the adjustment cost parameter $c$. When adjustments costs are high ( $c$ is small), the degree of dependence weakens and the situation is close to the CES case.

${ }^{27}$ In the opposite case, when the world price increases, it is on the interest of the profit-maximising producer to also increase its price against the backdrop of a higher demand for the non-tradable good.
} 
The above Phillips curve not only has the basic properties of [12] but also unambiguously captures important features of the empirical section. The slope $a_{\text {slope }, t}$ depends negatively on $\alpha_{t}$, the share of the imported good in the consumption basket, whereas the pass-through coefficient is directly related to $\alpha_{t}$. Since $\alpha_{t}$ increases as the relative price $q_{t}$ decreases, a drop of external prices (relative to home prices) causes the slope of the Phillips curve to fall and the pass-through coefficient to rise. The resizing of the weights in favour of the external components of the Phillips curve after the disinflation shock, exerts a more interesting dynamics to aggregate inflation. Besides and perhaps more importantly, the shock directly affects home price-setting, magnifying the response of aggregate inflation. Hence, in this case the pass-through effect of world price fluctuations is reinforced by the existence of the dragging effect.

\section{Monetary policy analysis}

In this section we embed the two types of inflation equations into a stylised, quarterly semistructural model. Then, we shock the system to study the policy implications of the dragging effect.

\subsection{A simple framework}

Equation [19] below establishes the link between the monetary policy interest rate instrument $i_{t}$ and the growth of real wages

$$
\Delta \varpi_{t}=b_{\varpi} \Delta \varpi_{t-1}+\left(1-b_{\varpi}\right) E_{t}\left[\Delta \varpi_{t+1}\right]-b_{r}\left(i_{t}-E_{t}\left[\pi_{t+1}\right]-r\right)+\epsilon_{\varpi, t}
$$

where $r$ is the equilibrium real interest rate (assumed fixed), $b_{\varpi} \in\langle 0,1\rangle$ and $b_{r}>0$. Typically this equation is specified in terms of the output gap and is interpreted as an IS curve ${ }^{28}$. However, in the absence of demand effects due to the assumed linearity of the production function, marginal costs solely depend on the real wage rate. The important feature of equation [19] is the negative relation between the real interest rate (gap) and the indicator of marginal cost used in our setup.

Equation [20] describes a plausible monetary policy rule that incorporates a concern about deviations of future expected inflation rates from the $\operatorname{target}^{29} \bar{\pi}$ and the measure ${ }^{30} \Delta \varpi_{t}$.

$$
i=(r+\bar{\pi})+f_{p}\left(\frac{1}{4} \sum_{j=0}^{3} E_{t}\left[\pi_{t+j}\right]-\bar{\pi}\right)+f_{w} \Delta \varpi_{t}+\epsilon_{i, t}
$$

where all coefficients are positive.

\footnotetext{
${ }^{28}$ See Clarida et.al. (1999)

${ }^{29}$ Inflation deviations enters the policy reaction function as a year-on-year figure. This not only smoothes the interest rate paths but is also consistent with the behaviour of a typical inflation targeter.

${ }^{30}$ We use this measure instead of a gap measure $\left(\varpi_{t}-\varpi\right)$ because $\Delta \varpi_{t}$ appears as a direct inflation determinant.
} 
Equation [21] is the definition of the relative price process

$$
q_{t}=q_{t-1}+\frac{1}{4}\left(\pi_{w, t}-\pi_{h, t}\right)
$$

Exchange rate dynamics is embedded into the model in two alternative forms,

$$
s_{t}= \begin{cases}s_{t-1}-\chi q_{t-1} & \text { PPP Model } \\ E_{t} s_{t+1}-\frac{1}{4}\left(i_{t}-\left\{r+f_{p}^{*} \pi_{t}^{*}+\left(1-f_{p}^{*}\right) \bar{\pi}\right\}\right) & \text { UIP Model }\end{cases}
$$

We choose these alternatives given the fact that there is no macroeconomic consensus about the correct nominal exchange rate model. However, despite our ignorance about how exchange rate dynamics actually evolves, we will show that the dragging effect is robust to exchange rate model uncertainty.

These two alternative specifications in [22] represent two extremes regarding the way the exchange rate adjusts to shocks. In the PPP model, the exchange rate moves only insofar as the real exchange rate is misaligned (i.e. whenever there are deviations from purchasing parity or disequilibria in the goods market). The parameter $\chi$ measures the speed of nominal exchange rate adjustments to real exchange rate deviations from its zero long-run steady-state value. Under this setting, the exchange shows a smoother and somewhat persistent dynamics. Also note that there will be no response on impact, since $s_{t}$ depends on lagged values of $q_{t}$.

In contrast, in the UIP case the spot exchange rate is a jump variable reacting to future expected values embedded in the interest rate differentials. Whenever current and expected interest rate differentials diverge too much, the spot exchange rate reacts in a manner that the non-arbitrage condition holds. Hence, to avoid undue jumps in the spot exchange rate, we allow the world nominal interest rate to move in response to world inflation shocks. Insofar as domestic and world interest rates will tend to move in the same direction, the spot exchange rate jump will not be magnified. This means that falling world inflation will decrease the world rate $^{31}$. In addition, it is worth mentioning that in general, the UIP model renders a more volatile exchange rate than the PPP model, with a non-zero response on impact.

The model also includes the law of motion of world inflation defined in equation [5] and is completed with a Phillips curve derived either for the CES-based (equation [12]) or the translog-based (equation [18]) framework.

We assume arbitrary but reasonable values for the model coefficients. In particular, in equation [19] we set $b_{\varpi}=0.7$ and $b_{r}=0.5$. In the policy rule [20], we choose the values $f_{p}=1.5$ and $f_{w}=0.5$. For the exchange rate equation [22] we use $\chi=0.36$ which implies a half-life of a misalignment of about a year. Also, we set $f_{p}^{*}=0.4$ which implies that the world interest rate reacts less than one-for-one to world inflation shocks. On the other hand, we consider

\footnotetext{
${ }^{31}$ In fact, the term in braces in the UIP model in [22] states that the world interest rate is set by the simple policy rule $i_{t}^{*}=(r+\bar{\pi})+f_{p}^{*}\left(\pi_{t}^{*}-\bar{\pi}\right)$.
} 
a steady-state real interest rate $r$ equal to 3 percent (which implies a value $\beta=0.97$ ) and a yearly steady-state inflation rate $\bar{\pi}$ equal to 2.5 percent. For the world inflation process, we make the autoregressive parameter $\rho=0.5$ which implies that the effect of a shock dies away in about a year.

For the CES case, the parameter that measures the degree of openness $\alpha$ is set to 0.35 , which roughly corresponds to the Chilean and Peruvian figures. For the translog case, the value of $\alpha$ is repeated while $\gamma=1$. Finally, the parameter $c$ is set such that the slopes of both Phillips curves are equal in steady state ${ }^{32}$.

\subsection{The exercise}

We perform two experiments regarding the way world disinflation may hit an economy initially resting on its steady state ${ }^{33}$. We first evaluate a one-period-only disinflation shock $\epsilon_{0}$ that brings world inflation from $\bar{\pi}=2.5$ to 1 percent on impact. This shock will illustrate the dynamics of the model. Second, we hit world inflation such that the level of world inflation remains at 1 percent for a year $(4 \text { quarters })^{34}$. Through this type of persistent shock we try to replicate the global disinflation phenomenon. We then compare the responses of the model variables under the two specifications for the Phillips curve ${ }^{35}$. We perform this exercise with the PPP model and then repeat the procedure with the UIP model.

\section{The PPP Model}

The results for inflation are displayed in Figure [3] where the first row depicts the responses under the one-quarter shock and the second, under the persistent one-year shock. The responses are consistent with the reasoning laid out in the theoretical section above. The CES specification produces a moderate fall while the translog case generates a deeper drop in aggregate inflation. The home inflation behaviour provides a better insight. We observe that it remains basically unperturbed in the CES case while the translog home inflation reacts in the same direction as the world inflation shock. In this case the falling world inflation drags the home inflation down, a fact that becomes even more apparent under the persistent shock.

In Figure [4] we show the effect on other three key variables for monetary policy: the real wage growth rate, the nominal interest rate and the nominal depreciation. Under both types of shocks, the monetary policy rule calls for a stronger, expansionary response of the policy instrument in the more disinflationary environment, i.e the translog case. The stronger response of interest rates in turn implies a stronger effect upon the real wage growth. It is

\footnotetext{
${ }^{32}$ This means that if we set $c=c^{\text {trans }}$ in the translog case, then $c^{\text {ces }}=\frac{c^{\text {trans }}}{2}\left[\frac{1+\beta}{1+\beta+c^{\text {trans }}}\right]$.

${ }^{33}$ To solve the rational expectations equilibrium, we use the algorithm outlined in Klein (2000).

${ }^{34}$ To do this we simulate the model subject to the following history of world inflation shocks:

$\epsilon_{j}= \begin{cases}1-\bar{\pi} & \text { for } j=0 \\ (1-\rho) \epsilon_{0} & \text { for } j=1,2,3 \\ 0 & \text { otherwise }\end{cases}$

${ }^{35}$ Additionally, we shocked the model considering different sizes and signs for the shocks in order to exploit the non-linearities in [18]. Although we did find differences in the responses of the endogenous variables, none of them were sizeable enough to be reported.
} 
remarkable that although monetary policy performs in an unduly expansionary way, the effect upon inflation is flimsy.

In Figure [5] we plot the reasons behind the weakening of monetary policy in the translog setting: the effect of the shocks upon the slope of the Phillips curve $a_{\text {slope }, t}$ and the passthrough parameter $\alpha_{t}$. Under both transitory and permanent shocks, the slope of the Phillips curve co-moves with the relative price whereas the pass-through moves in the opposite direction. Both, the reduction of the Phillips curve slope and the increase in pass-through reinforce the dragging effect vis-a-vis the reduction of monetary policy power.

These results are in line with the two key features observed in the empirical part: the positive correlation between the slope of the Phillips curve and the real exchange rate and the negative correlation between the pass-through and this relative price.

\section{The UIP Model}

In Figures [6] and [7] we present the responses of the different variables under the UIP model. It is important to recall that the main difference relative to the previous results is originated in the response of the nominal exchange rate. As it can be seen, the shock causes a strong depreciation on impact, since a cut in the interest rate as a policy reaction is anticipated. The depreciation of the nominal exchange rate more than offsets the shock so that the world inflation in pesos raises. Under translog preferences, this leads to an increase in the domestic inflation and, finally, turns into a higher aggregate inflation.

Nonetheless, after the shock, the dragging effect operates and the results are qualitatively the same as the ones obtained in the PPP model. Note, however, that the huge depreciation on impact under the persistent shock calls for a subsequent appreciation that magnifies the dragging effect of the disinflation shock.

\section{$5 \quad$ Final remarks}

This paper provides a simple theoretical explanation of how the current world disinflation might have dragged down domestic inflation levels in some small open economies. In particular, we empirically find such an effect in New Zealand, Chile and Peru during the last decade. We argue that globalisation and the increasing availability of cheaper foreign goods make world prices ever more important to the price setting of domestic non-tradable goods. This is what we call the dragging effect.

The dragging effect causes the contribution of domestic factors on aggregate inflation to reduce due to demand substitution in favour of foreign goods. Since domestic expenditure in tradable goods increases relative to that of non-tradables, the usual demand (interest rate) channel of monetary policy also loses importance in the determination of prices. Thus, monetary policy suffers a loss of effectiveness to affect inflation. 
We argue that translog preferences are able to capture the strategic complementarity that leads to the dragging effect. In our disinflation experiments, translog preferences fare better than the usual CES preferences, since the latter cannot replicate the follow up behaviour in price setting. To follow up is the best action home price setters can do to avoid loosing market share in an increasingly competitive environment.

A natural extension of the paper is to move the model economy towards a more detailed general equilibrium framework to better understand the impact of the dragging effect. For instance, to have a better insight of the labour market and its relation to marginal costs. In this case, a shock that pushes down the relative price of tradables to non-tradables might expand the demand in the tradable sector and reduce that of the non-tradable sector. This could lower non-tradable sector real wages (relative to those of the tradable sector) and hence reduce home good prices, making the dragging effect even more pronounced than what is suggested here.

The existence of the dragging effect has important consequences for monetary policy in small open economies, since it can lead the economy to a low-inflation trap. In this circumstance, the direct interest channel is barely useful and the pass-through gains strength, so policy makers may find convenient to induce exchange rate depreciation as a way out of the trap. 


\section{References}

[1] Andersen, Palle and William Wascher (2000), "Understanding the Recent Behaviour of Inflation: An Empirical Study of Wage and Price Developments in Eight Countries", BIS paper No. 3, 267-302.

[2] Ascari, Guido (2000), "Staggered Price and Trend Inflation: Some Nuisances", Mimeo, University of Pavia.

[3] Bakhshi, Hasan, Pablo Burriel-Llombart, Hashmat Khan and Barbara Rudolf (2003), "Endogenous Price Stickiness, Trend Inflation, and the New Keynesian Phillips Curve", Bank of England Working Paper No. 191.

[4] Banerjee, Anindya and Bill Rusell (2003), "A Reinvestigation of the Markup and the Business Cycle", Economic Modelling, forthcoming.

[5] Batini, Nicoletta, Brian Jackson and Stephen Nickell, (2000), "Inflation Dynamics and the Labour Share in the UK", Bank of England External MPC Unit Discussion Paper No. 2 .

[6] Bénabou, Roland (1992), "Inflation and Markups: Theories and Evidence from the Retail Trade Sector", European Economic Review, 36, 566-574.

[7] Bergin, Paul and Robert Feenstra (2000), "Staggered Price Setting, Translog Preferences, and Endogenous Persistence", Journal of Monetary Economics, 45, 657-680.

[8] Bergin, Paul and Robert Feenstra (2001), "Pricing-to-market, Staggered Contracts, and Real Exchange Rate Persistence", Journal of International Economics, 54, 333-359.

[9] Bowman, David (2003), "Market Power and Inflation", International Finance Discussion Papers No. 783, Board of Governors of the Federal Reserve System.

[10] Broda, Christian and David Weinstein (2004), "Globalization and the Gains from Variety", Staff Report No. 180, Federal Reserve Bank of New York.

[11] Calvo, Guillermo, Oya Celasun and Michael Kumhof (2003), "Inflation Inertia and Credible Disinflation - The Open Economy Case", NBER Working Paper No. 9557.

[12] Clarida, Richard, Jordi Gali and Mark Gertler (1999), "The Science of Monetary Policy: A New Keynesian Perspective", Journal of Economic Literature, 37, 1661-1707.

[13] Clark, Peter and Douglas Laxton (1997), "Phillips Curves, Phillips Lines and the Unemployment Cost of Overheating", IMF Working Paper No. 97/17.

[14] Deaton, Angus and John Muellbauer (1980), "An Almost Ideal Demand System", American Economic Review, 70, 312-326.

[15] Dupasquier, Chantal and Nicholas Ricketts (1998), "Non-Linearities in the OutputInflation Relationship" in Price Stability, Inflation Targets, and Monetary Policy: Proceedings of a conference held by the Bank of Canada in May 1997, 131-173. 
[16] Goldfjan, Ilan and Sérgio Ribeiro (2000), "The Pass-through from Depreciation to Inflation: A Panel Study", Banco Central Do Brasil Working Paper No. 5.

[17] Harvey, Andrew (1989), Forecasting Structural Models and the Kalman Filter, Cambridge, Cambridge University Press.

[18] Jonsson, Magnus and Stefan Palmqvist (2003), "Inflation, Markups and Monetary Policy", Sveriges Riksbank Working Paper No. 148.

[19] Kamada, Koichiro and Naohisa Hirakata (2002), "Import Penetration and Consumer Prices", Bank of Japan Research and Statistics Department Working Paper Series 0201.

[20] King, Robert and Mark Watson (1994), "The Post-war U.S. Phillips Curve: A Revisionist Econometric History", Carnegie-Rochester Conference Series on Public Policy, 41, 157219.

[21] Klein, Paul (2000), "Using the Generalized Schur Form to Solve a Multivariate Linear Rational Expectation Model", Journal of Economics Dynamics and Control, 24, 14051423 .

[22] Mankiw, Gregory and Ricardo Reis (2001), "Sticky Information versus Sticky Prices", NBER Working Paper No. 8290.

[23] Razin, Assaf and Chin-Wa Yuen (2001), "The 'New Keynesian' Phillips Curve: Closed Economy vs. Open Economy", NBER Working Paper No. 8313.

[24] Rogoff, Keneth (2003), "Globalization and Global Disinflation", in Monetary Policy and Uncertainty: Adapting to a Changing Economy, proceedings of the 2003 Jackson Hole symposium sponsored by the Federal Reserve Bank of Kansas City.

[25] Romer, David (1993), "Openness and Inflation: Theory and Evidence", The Quarterly Journal of Economics, 108, 869-903.

[26] Rotemberg, Julio (1982), "Sticky Prices in the United States," Journal of Political Economy, 60, 1187-1211.

[27] Rotemberg, Julio and Michael Woodford (1991), "Mark-ups and the Business Cycle", in Blanchard, O. and Fisher, S (eds), NBER Macroeconomics Annual, 63-128.

[28] Sargent, Thomas (1979), Macroeconomic Theory, New York, Academic Press.

[29] Taylor, John (2000), "Low Inflation, Pass-through and the Pricing Power of Firms", European Economic Review, 44, 1389-1408. 


\section{Appendix A: Flexible price setting}

\section{The CES case}

The consumption basket is given by

$$
C_{t}=\left[(1-\alpha)^{\frac{1}{\eta}} C_{h, t}^{\frac{\eta-1}{\eta}}+\alpha^{\frac{1}{\eta}} C_{w, t}^{\frac{\eta-1}{\eta}}\right]^{\frac{\eta}{\eta-1}}
$$

where $C_{h, t}$ and $C_{w, t}$ denote the quantity of domestic and imported goods respectively. Standard intratemporal choice condition for the home good implies

$$
C_{h, t}=(1-\alpha)\left(\frac{P_{h, t}}{P_{t}}\right)^{-\eta} C_{t}
$$

which is the version in levels of [3] in the main text.

After imposing the condition $Y_{h, t}=C_{h, t}$ and replacing equations [6] and [A2] in [7] we obtain the monetary profits

$$
B\left(P_{h, t}\right)=(1-\alpha)\left(P_{h, t}-W_{t}\right)\left(\frac{P_{h, t}}{P_{t}}\right)^{-\eta} C_{t}
$$

The function $[\mathrm{A} 3]$ is maximised by the rule

$$
P_{h, t}^{c e s}=\left(\frac{\eta}{\eta-1}\right) W_{t}
$$

which is the version in levels of [8].

\section{The translog case}

We first define the log expenditure function as a sum of log aggregate consumption and log consumption-based price index:

$$
e_{t}=c_{t}+p_{t}
$$

Given that we are only treating a two-goods case, the price aggregator $p_{t}$ is defined as equation [13],

$$
p_{t}=(1-\alpha) p_{h, t}+\alpha p_{w, t}-\frac{\gamma}{2}\left(p_{w, t}-p_{h, t}\right)^{2}
$$

The compensated demand for the domestic good can be easily determined using Shephard's Lemma 


$$
C_{h, t}=\frac{\partial E_{t}}{\partial P_{h, t}}=\frac{E_{t}}{P_{h, t}} \frac{\partial e_{t}}{\partial p_{h, t}}=\frac{E_{t}}{P_{h, t}}\left(1-\alpha+\gamma q_{t}\right)
$$

After replacing the version in levels of identity [A5] we obtain the demand for the home good

$$
C_{h, t}=\left(1-\alpha+\gamma q_{t}\right)\left(\frac{P_{h, t}}{P_{t}}\right)^{-1} C_{t}
$$

which is the version in levels of [14]. In this case, the profit function is

$$
B\left(P_{h, t}\right)=\left(1-\alpha+\gamma q_{t}\right)\left(P_{h, t}-W_{t}\right)\left(\frac{P_{h, t}}{P_{t}}\right)^{-1} C_{t}
$$

The optimal price level solves the first order condition

$$
P_{h, t}^{\text {trans }}=\left(1-\frac{1-\alpha+\gamma q_{t}}{\gamma}\right) W_{t}
$$

Equation [A10] cannot be solved explicitly for $P_{h, t}^{\text {trans }}$ since $q_{t}$ depends on $p_{h, t}^{\text {trans }}=\ln \left(P_{h, t}^{\text {trans }}\right)$. However we can approximate the optimal price by taking logs,

$$
p_{h, t}^{\text {trans }}=\ln \left(1-\frac{1-\alpha+\gamma q_{t}}{\gamma}\right)+w_{t}
$$

and using the fact that for a small number $x, \ln (1-x) \simeq x$, then

$$
p_{h, t}^{\text {trans }}=\frac{1-\alpha}{2 \gamma}+\frac{p_{w, t}}{2}+\frac{w_{t}}{2}
$$

After differentiation of [A12] we get equation [16] in the text. 


\section{Appendix B: Price setting with adjustment costs}

The quadratic approximation of the monetary profit (equation [7]) around its desired price level $P_{h, t}^{*}$ (either the CES or translog) is

$$
B\left(P_{h, t}^{*}\right) \simeq B\left(P_{h, t}^{*}\right)+B^{\prime}\left(P_{h, t}^{*}\right)\left(P_{h, t}-P_{h, t}^{*}\right)+c_{a}\left(p_{h, t}-p_{h, t}^{*}\right)^{2}
$$

where $c_{a}=-\frac{1}{2} B^{\prime \prime}\left(P_{h, t}^{*}\right)\left(P_{h, t}^{*}\right)^{-2}>0$. The linear term disappears due to the optimality of $P_{h, t}^{*}$ while the constant term is irrelevant to the firms' decision-making.

On the other hand, the adjustment costs for price changes are given by

$$
\text { AdjCost }=c_{b}\left(p_{h, t}-p_{h, t-1}\right)^{2}
$$

Therefore, in the presence of adjustment costs, the firm pricing problem can be reformulated as an overall minimisation problem

$$
\min _{\left\{p_{h, s}\right\}_{s=t \ldots \infty}} E_{t}\left[\sum_{s=t}^{\infty} \beta^{s-t}\left\{\left(p_{h, s}-p_{h, s}^{*}\right)^{2}+\frac{1}{2 c}\left(p_{h, s}-p_{h, s-1}\right)^{2}\right\}\right]
$$

subject to the transversality condition

$$
\lim _{s \rightarrow \infty} \beta^{s}\left[\left(E_{t} p_{h, s}-E_{t} p_{h, s}^{*}\right)+\frac{1}{2 c}\left(E_{t} p_{h, s}-E_{t} p_{h, s-1}\right)\right]=0
$$

where $\frac{1}{2 c}=\frac{c_{b}}{c a}>0$.

To solve the firms problem, we consider the Euler equation in period $t$,

$$
2 c\left(E_{t} p_{h, t}-E_{t} p_{h, t}^{*}\right)+\left(E_{t} p_{h, t}-E_{t} p_{h, t-1}\right)-\beta\left(E_{t} p_{h, t+1}-E_{t} p_{h, t}\right)=0
$$

The operator $E_{t}$ is the expectation conditional on the information set accumulated up to time $t$ when the pricing decision is made. Equation [B3] describes the optimal price plan of the firm. On the basis of the information set, the lagged price level $p_{h, t-1}$ is a predetermined variable while the firm sets $p_{h, t}=E_{t} p_{h, t}$ which is actually observed. If we want to track the actual evolution of $p_{h, t}$ we need to set up the system of Euler equations as

$$
2 c\left(p_{h, s}-p_{h, s}^{*}\right)+\left(p_{h, s}-p_{h, s-1}\right)-\beta\left(E_{s} p_{h, s+1}-p_{h, s}\right)=0 \text { for } s=t, t+1, \ldots
$$

Due to rational expectations, the next period price forecasting error based on this period information set is an iid sequence of random variable, $E_{s} p_{h, s+1}-p_{h, s+1}=\frac{2 c}{\beta} \xi_{s+1}$. Replacing and reordering conveniently yields 


$$
\left[1-\frac{(2 c+1+\beta)}{\beta} L+\frac{1}{\beta} L^{2}\right] p_{h, t+1}=-\left(\frac{2 c}{\beta}\right)\left(p_{h, t}^{*}+\xi_{t+1}\right)
$$

where $L$ denotes the lag operator, $L^{j} p_{h, t}=p_{h, t-j}$. Following Sargent (1979), the lag-polynomial in brackets can be factorized as

$$
\left[1-\frac{(2 c+1+\beta)}{\beta} L+\frac{1}{\beta} L^{2}\right]=\left(1-\lambda_{1} L\right)\left(1-\lambda_{2} L\right)
$$

This factorization implies that

$$
\lambda_{1}+\lambda_{2}=\frac{(2 c+1+\beta)}{\beta} \text { and } \lambda_{1} \lambda_{2}=\frac{1}{\beta}
$$

The standard solution for the roots of this polynomial are such that $0<\lambda_{1}<1$ and $\lambda_{2}>\frac{1}{\beta}$ : one stable solution and the other explosive. Upon inspection of the above two equations in $\lambda_{1}$ and $\lambda_{2}$, it is easy to verify that:

$$
\beta \lambda_{1}^{2}+1-2 c \lambda_{1}=(1+\beta) \lambda_{1}
$$

Replacing the factorized polynomial and multiplying by $\left(1-\lambda_{2} L\right)^{-1}$ allows us to get

$$
\left(1-\lambda_{1} L\right) p_{h, t+1}=-\left(1-\lambda_{2} L\right)^{-1}\left(\frac{2 c}{\beta}\right)\left(p_{h, t}^{*}+\xi_{t+1}\right)
$$

After expanding the inverse lag operator polynomial on the right hand side ${ }^{36}$ the expression becomes

$$
p_{h, t}=\lambda_{1} p_{h, t-1}+\frac{2 c}{\beta} E_{t}\left[\sum_{j=t}^{\infty}\left(\frac{1}{\lambda_{2}}\right)^{j-t+1} p_{h, j}^{*}\right]+d\left(\lambda_{2}\right)^{t}
$$

The transversality condition makes $d=0$, so we can express the price decision as

$$
p_{h, t}=\lambda_{1} p_{h, t-1}+\frac{2 c}{\beta} E_{t}\left[\sum_{j=t}^{\infty}\left(\beta \lambda_{1}\right)^{j-t+1} p_{h, j}^{*}\right]
$$

This is the key solution to the problem. To derive an inflation process, we forward [B7] one period, take time $t$ expectations and multiply by $\beta \lambda_{1}$,

\footnotetext{
${ }^{36}$ Note that since $\lambda_{2}>1$ the expansion is $\left(1-\lambda_{2} L\right)^{-1}=-\frac{1}{\lambda_{2}} L^{-1}-\left(\frac{1}{\lambda_{2}}\right)^{2} L^{-2}-\left(\frac{1}{\lambda_{2}}\right)^{3} L^{-3}+\ldots$
} 


$$
\beta \lambda_{1} E_{t}\left[p_{h, t+1}\right]=\beta\left(\lambda_{1}\right)^{2} p_{h, t}+\frac{2 c}{\beta} E_{t}\left[\sum_{j=t+1}^{\infty}\left(\beta \lambda_{1}\right)^{j-t+1} p_{h, j}^{*}\right]
$$

Then, taking [B7] out of [B8], rearranging and differentiating

$$
\left(1+\beta \lambda_{1}^{2}\right) \pi_{h, t}=\beta \lambda_{1} E_{t} \pi_{h, t+1}+\lambda_{1} \pi_{h, t-1}+2 c \lambda_{1} \Delta p_{h, t}^{*}+i i d
$$

The optimal price $p_{h, t}^{*}$ depends on the consumption aggregator assumed.

\section{The CES case}

According to equation [9], $\Delta p_{h, t}^{*}=\Delta p_{h, t}^{c e s}=\Delta w_{t}=\Delta \varpi_{t}+\pi_{h, t}$, so that equation [B9], after some trivial manipulation, becomes

$$
\left[1+\beta \lambda_{1}^{2}-2 c \lambda_{1}\right] \pi_{h, t}=\beta \lambda_{1} E_{t} \pi_{h, t+1}+\lambda_{1} \pi_{h, t-1}+2 c \lambda_{1} \Delta \varpi_{t}+\beta \lambda_{1} \varepsilon_{t}
$$

Considering equation [B6] allows us to obtain equation [11] in the main text that does not depend on $\lambda_{1}$ due to the assumed linearity of the production function. It is now straightforward to aggregate the inflation dynamics to get the overall inflation rate using the aggregator in [4].

\section{The translog case}

Now we replace $\Delta p_{h, t}^{*}=\Delta p_{h, t}^{\text {trans }}=\frac{1}{2} \pi_{w, t}+\frac{1}{2} \Delta w_{t}=\frac{1}{2} \pi_{w, t}+\frac{1}{2} \Delta \varpi_{t}+\frac{1}{2} \pi_{h, t}$ in equation [B9] to obtain

$$
\left[1+\beta \lambda_{1}^{2}-c \lambda_{1}\right] \pi_{h, t}=\beta \lambda_{1} E_{t} \pi_{h, t+1}+\lambda_{1} \pi_{h, t-1}+c \lambda_{1} \pi_{w, t}+c \lambda_{1} \Delta \varpi_{t}+\beta \lambda_{1} \varepsilon_{t}
$$

Again, the equality [B6] permits us to simplify equation [B11] into [17]. Then, after aggregating with [15] we get the time-varying Phillips curve [18]. 

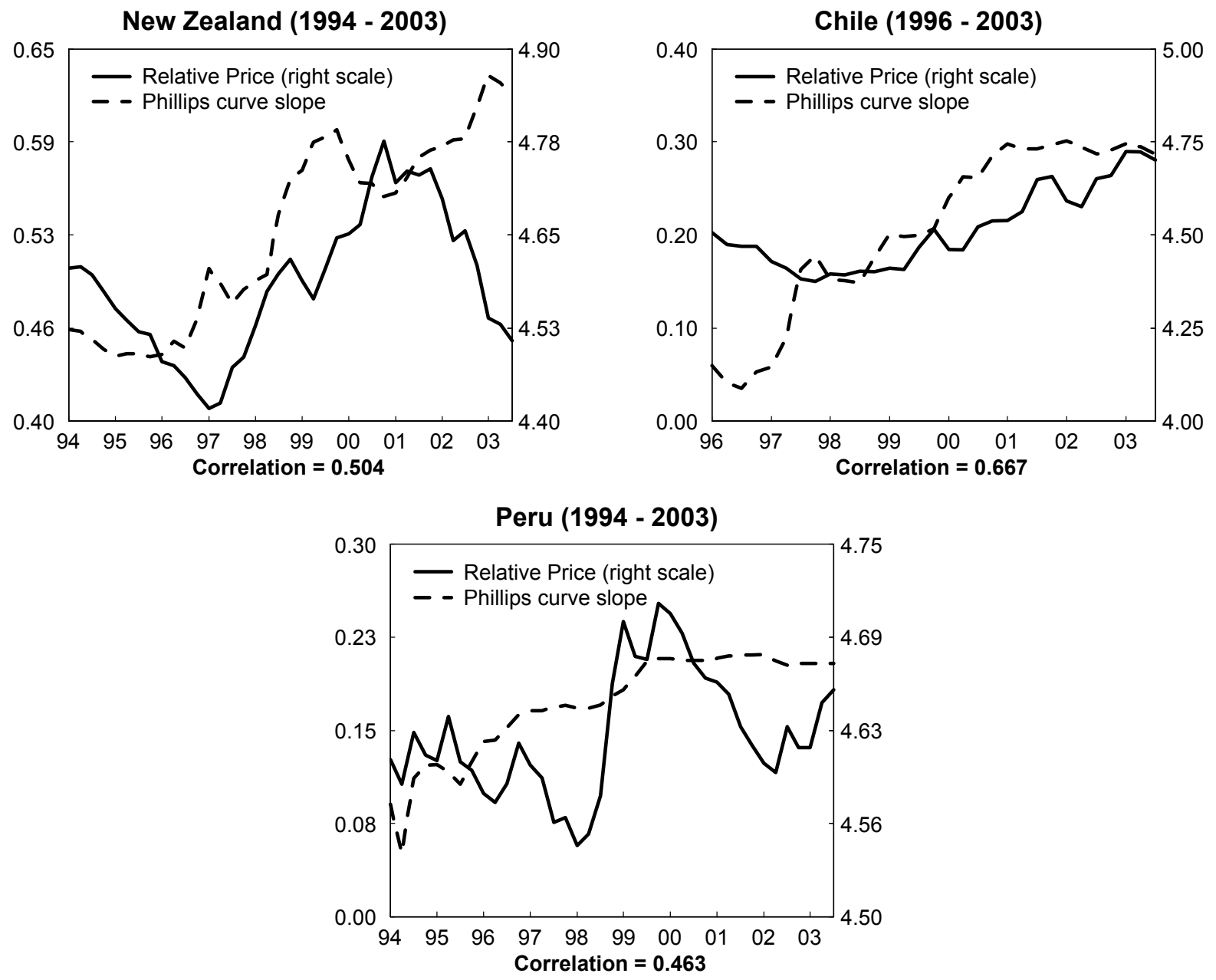

Figure 1: Phillips curve slope and real exchange rate 

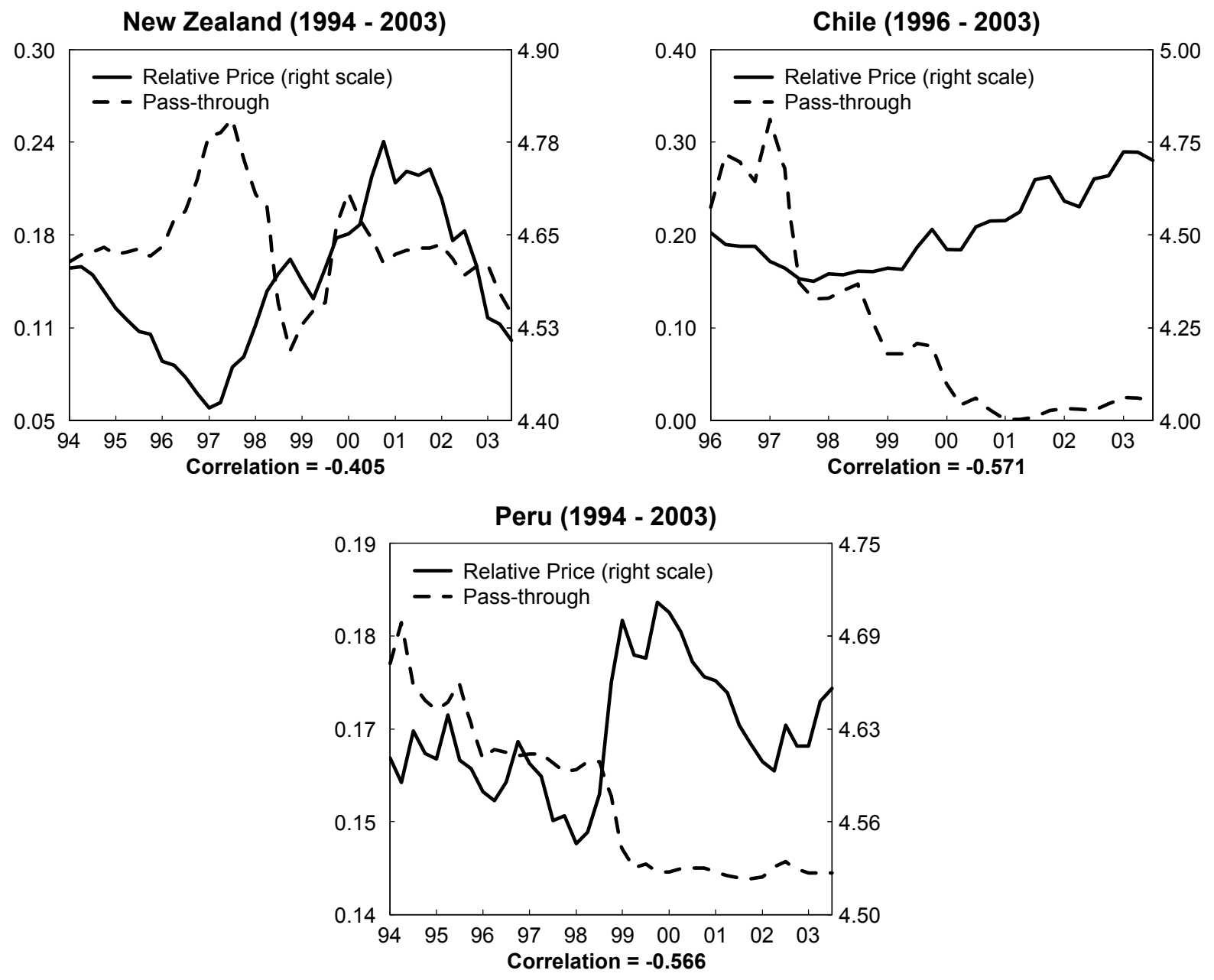

Figure 2: Pass-through and real exchange rate 

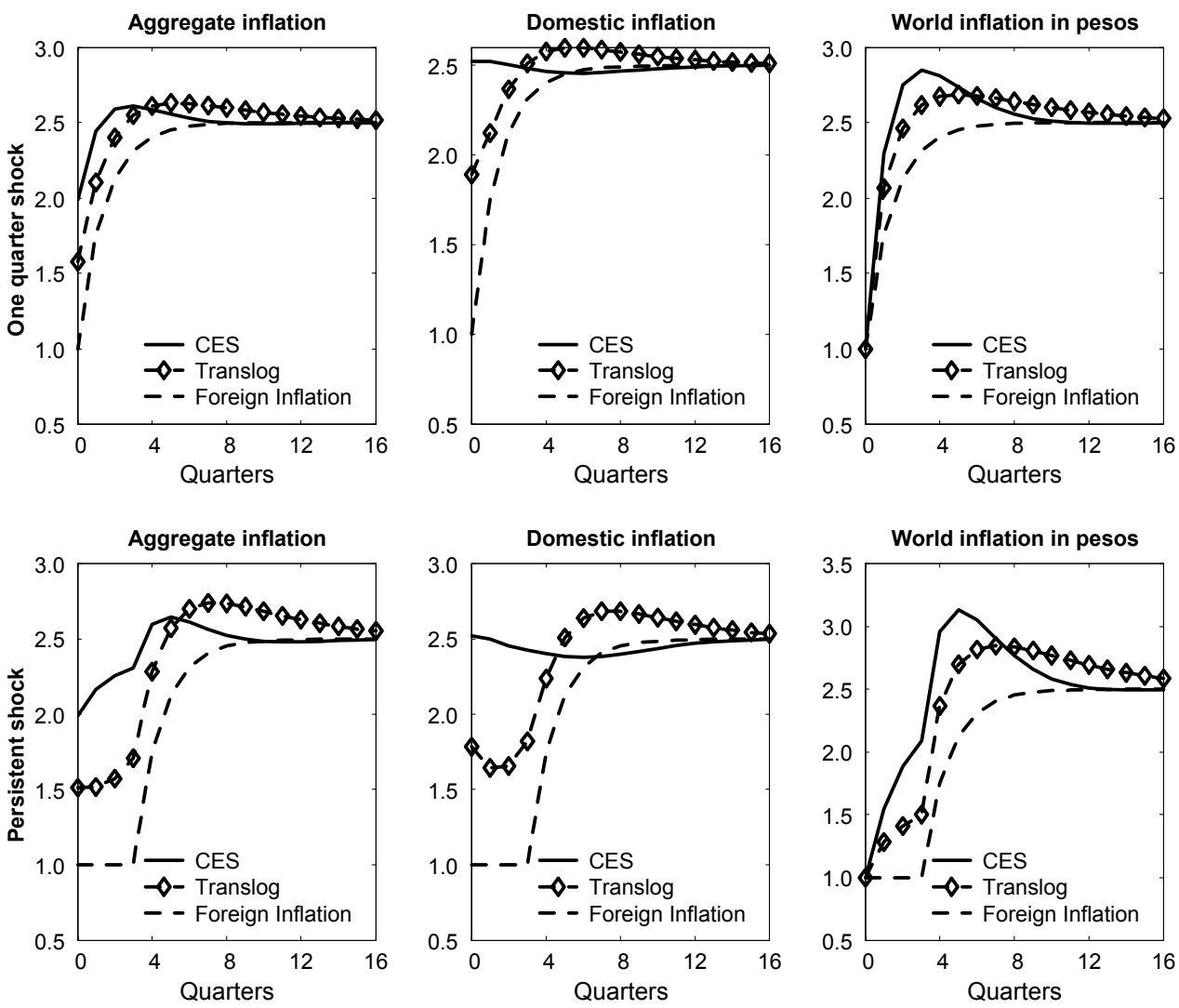

Figure 3: Inflation responses to transitory and persistent shocks to world inflation (PPP case). 

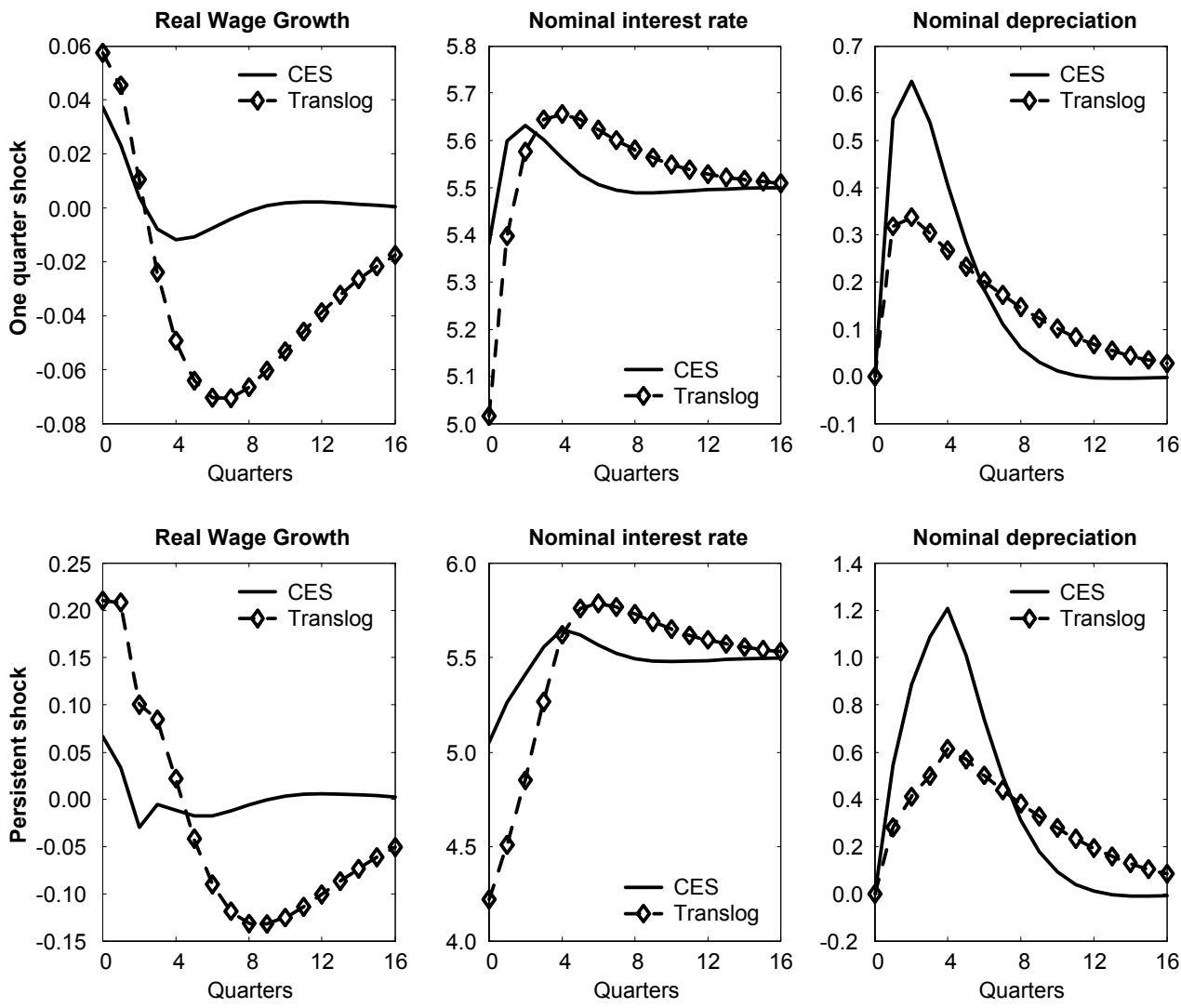

Figure 4: Real wage growth, interest rate and exchange rate responses to transitory and persistent shocks to world inflation (PPP case). 

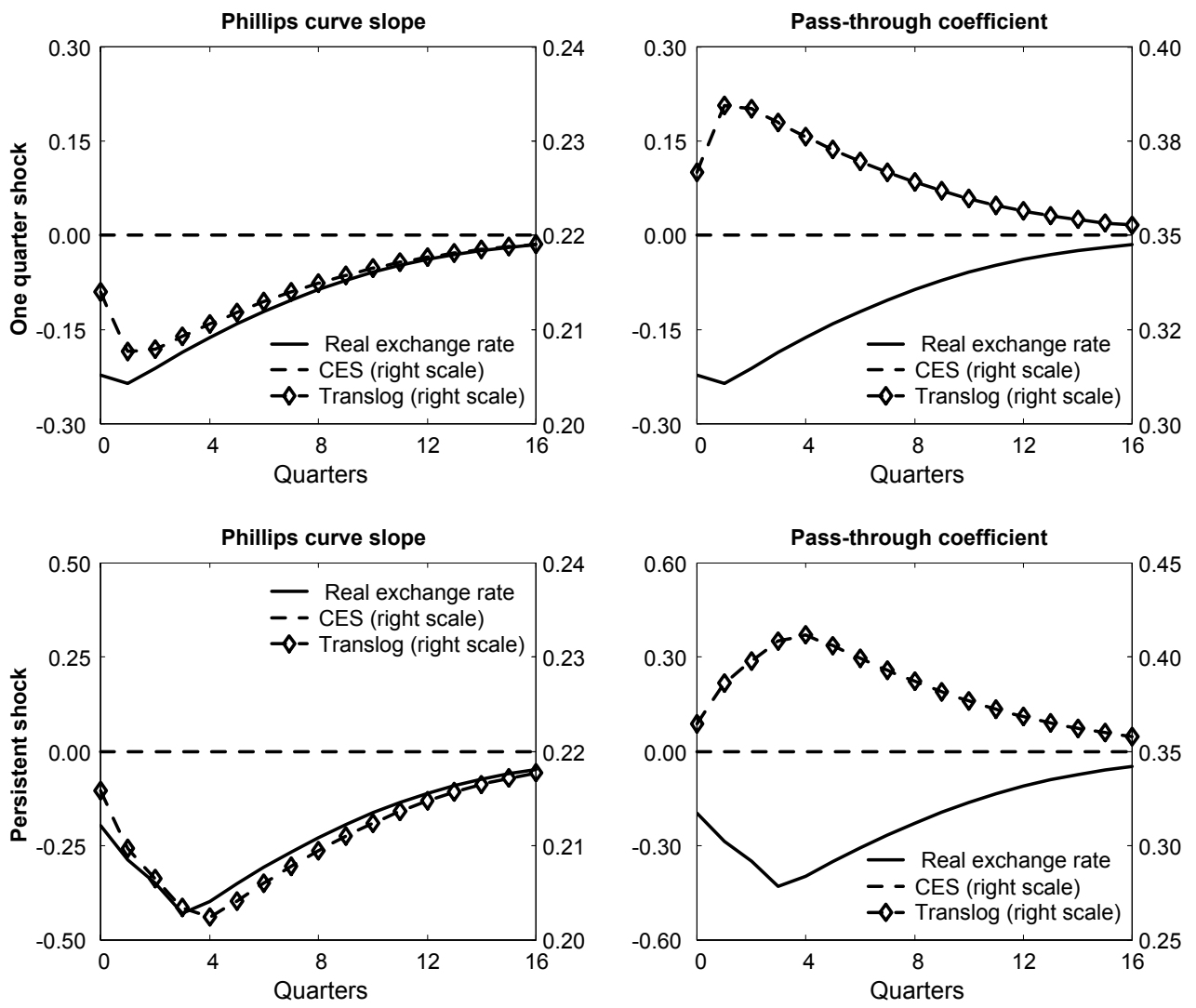

Figure 5: Time-varying parameters with transitory and persistent shocks to world inflation (PPP case). 

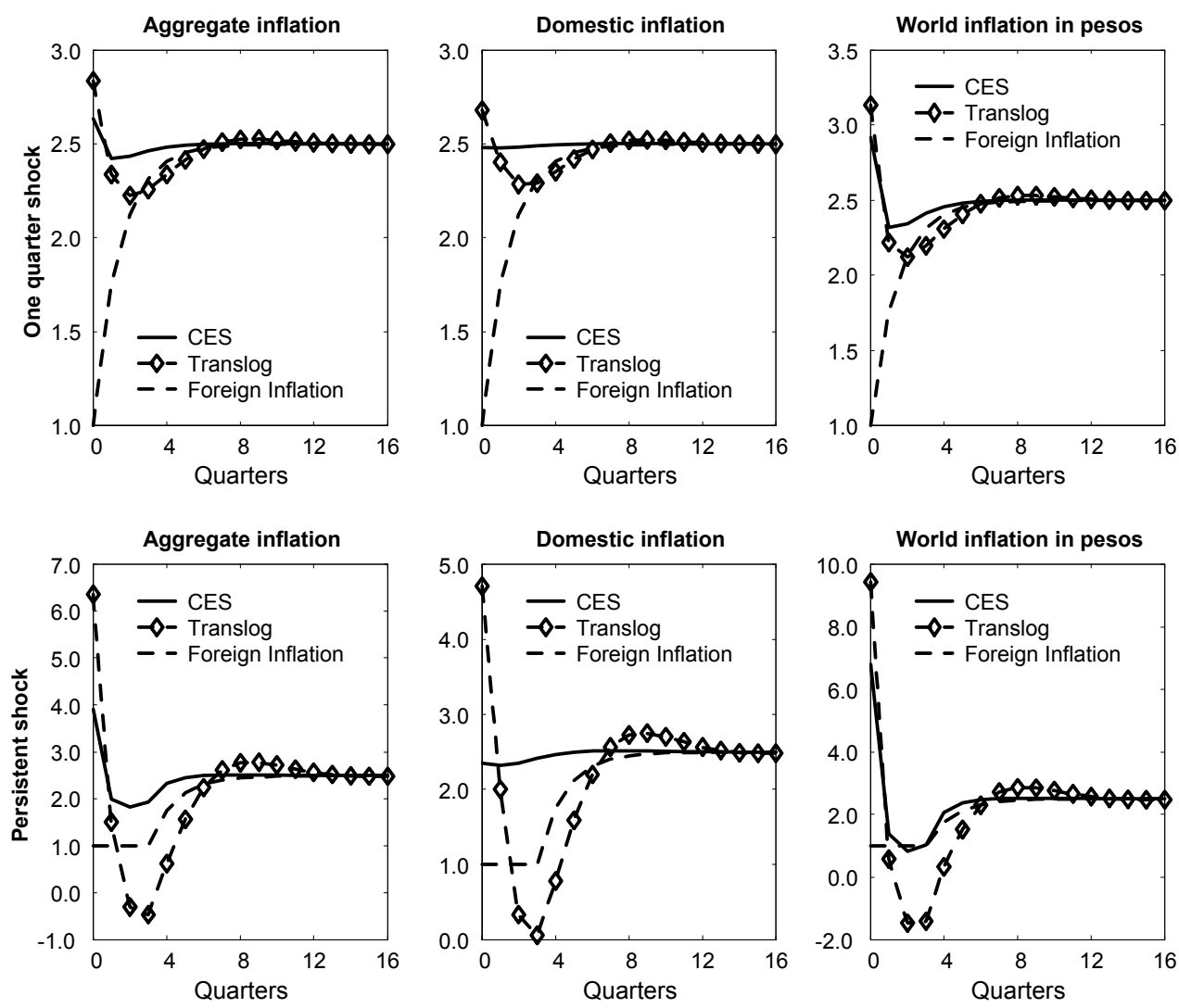

Figure 6: Inflation responses to transitory and persistent shocks to world inflation (UIP case). 

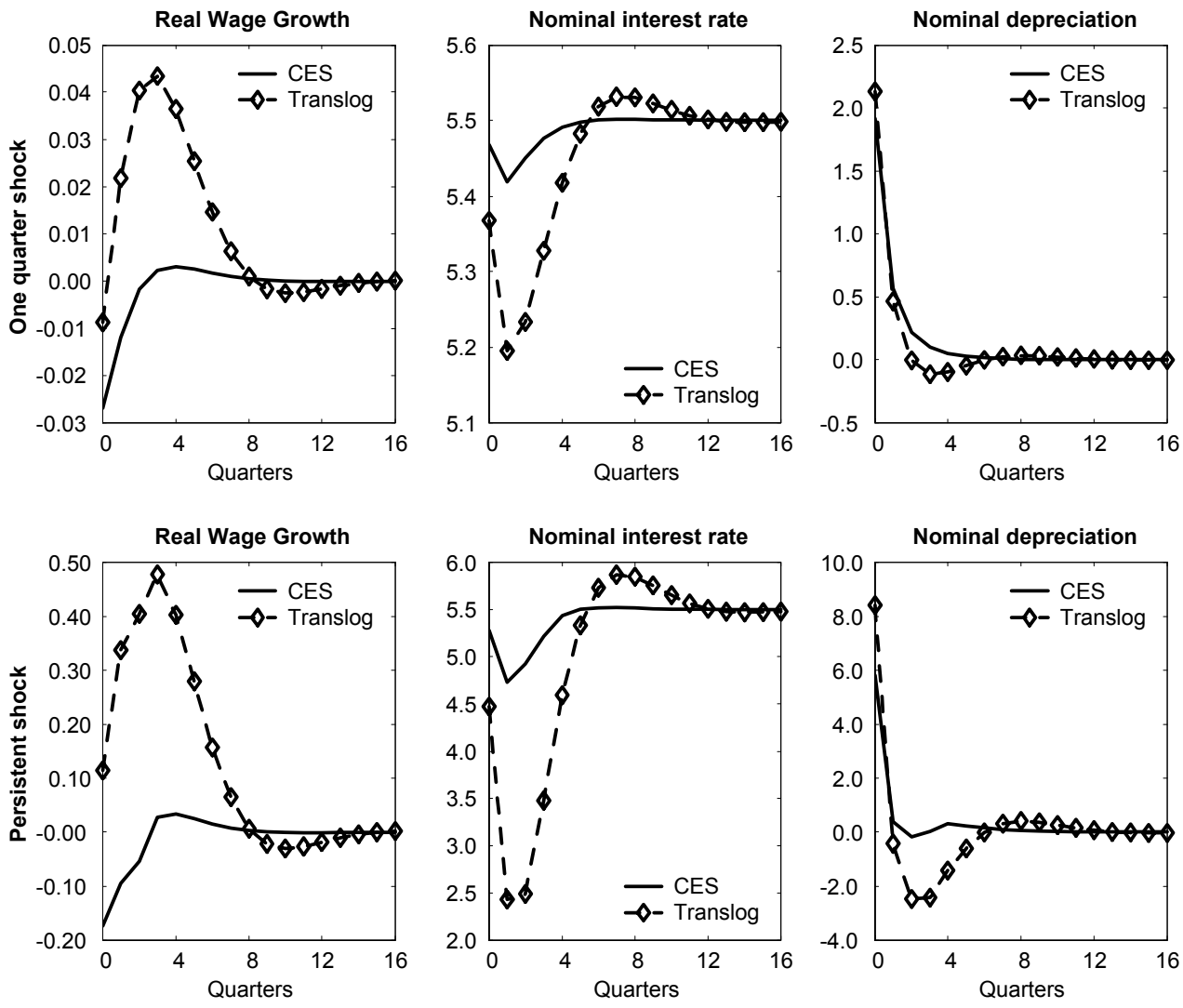

Figure 7: Real wage growth, interest rate and exchange rate responses to transitory and persistent shocks to world inflation (UIP case). 

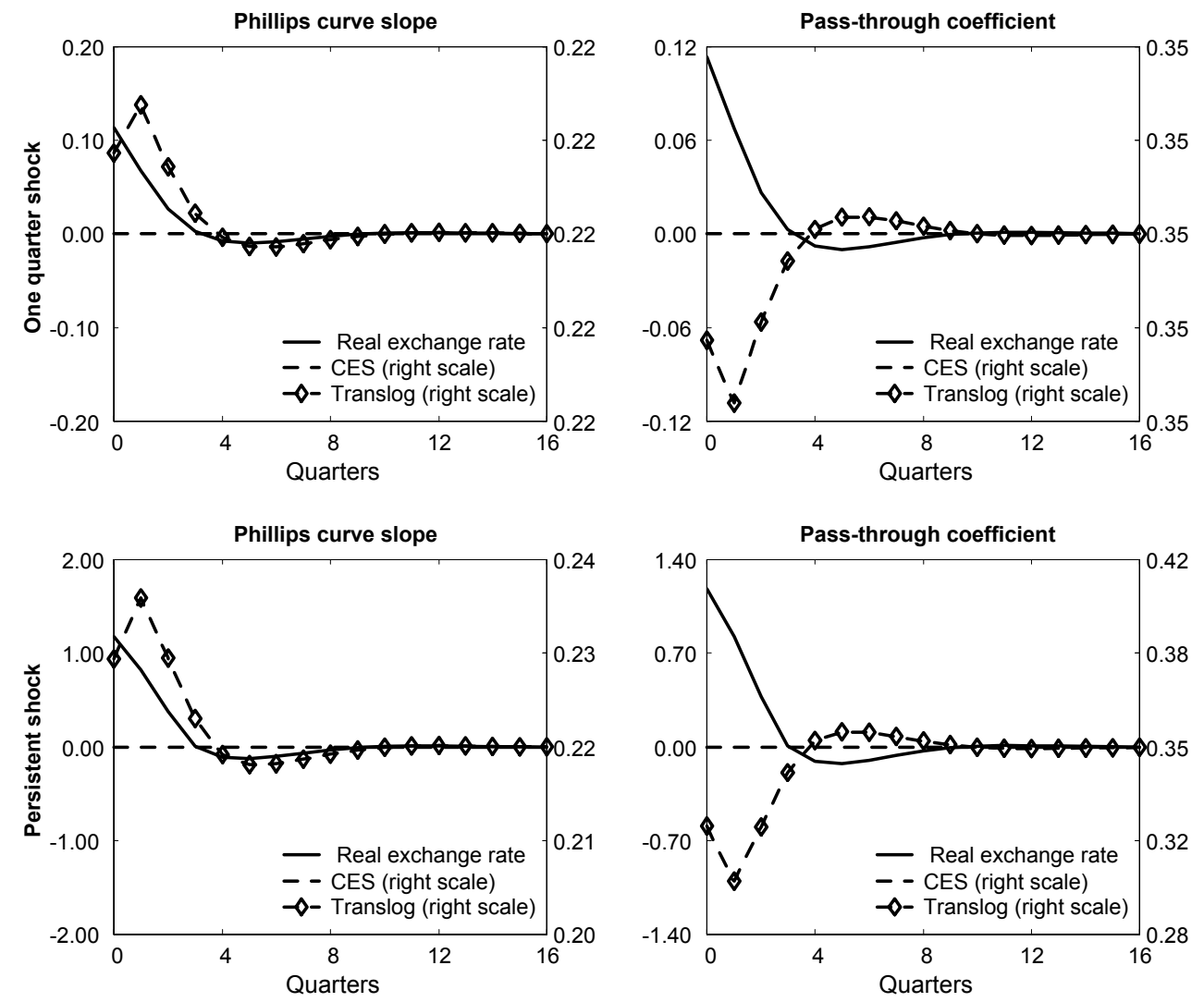

Figure 8: Time-varying parameters with transitory and persistent shocks to world inflation (UIP case). 